\title{
Efficacy and safety of thalidomide on psychological symptoms and sleep disturbances in the patient with refractory ankylosing spondylitis
}

\author{
Shengli Zhang ${ }^{1,2 \#}$, Zhihan Chen ${ }^{1,2 \#}$, Yanfang $W_{u^{1,2}}$, Diantian Lin ${ }^{1,2}$, Juanjuan He ${ }^{1,2}$, Jianwen Liu ${ }^{1,2}$, \\ Fei Gao ${ }^{1,2}$, He Lin ${ }^{1,2}$ \\ ${ }^{1}$ Department of Rheumatology, Fujian Provincial Hospital, Fuzhou, China; ${ }^{2}$ Department of Rheumatology, Shengli Clinical Medical College of \\ Fujian Medical University, Fuzhou, China \\ Contributions: (I) Conception and design: S Zhang, F Gao; (II) Administrative support: Y Wu; (III) Provision of study materials or patients: D Lin, H \\ Lin; (IV) Collection and assembly of data: J He, J Liu; (V) Data analysis and interpretation: J Liu, H Lin; (VI) Manuscript writing: All authors; (VII) \\ Final approval of manuscript: All authors. \\ "These authors contributed equally to this work. \\ Correspondence to: Shengli Zhang; Fei Gao. Department of Rheumatology, Fujian Provincial Hospital, No. 134, The East Street, Drum Tower \\ District, Fuzhou 350000, China. Email: slzhang301@163.com; feifei7316749@aliyun.com.
}

Backgrounds: Thalidomide has been used to treat ankylosing spondylitis (AS) patients, but the efficacy and safety of thalidomide on psychological symptoms and sleep disturbances in the patient with refractory AS has not been evaluated.

Methods: In this 6-month open study, 35 cases of patients with refractory AS were recruited, using thalidomide at a dose of $150 \mathrm{mg} / \mathrm{d}$ before sleep. Bath Ankylosing Spondylitis Disease Activity Index (BASDAI), Bath Ankylosing Spondylitis Functional Index (BASFI), Bath Ankylosing Spondylitis Metrology Index (BASMI), fingertip-to-floor distance, nocturnal pain, total back pain, psychological symptoms, and sleep were assessed at baseline, 3 and 6 months respectively.

Results: Clinical parameters, included BASDAI, BASFI, fingertip-to-floor distance, nocturnal pain, total back pain, ESR, CRP, SAS, SDS and PSQI lower levels of month 3 were found when compared to initial levels $(\mathrm{P}<0.05)$. In the 6th month, the levels of BASDAI, fingertip-to-floor, nocturnal pain, total back pain, SDS were further lower than those in the $3 \mathrm{rd}$ month $(\mathrm{P}<0.05)$. The levels of BASMI were lower than this at baseline $(\mathrm{P}<0.05)$. The most tolerable common adverse reactions were drowsiness $(10 / 35)$, dry mouth $(8 / 35)$, constipation (8/35), dandruff (7/35), dizziness (4/35).

Conclusions: Thalidomide can improve effectiveness and safety in the treatment of physical, as well as psychological symptoms and sleep disturbances accompanying refractory AS.

Keywords: Thalidomide; psychological symptoms; sleep disturbances; refractory ankylosing spondylitis (refractory AS)

Submitted Oct 23, 2019. Accepted for publication Nov 18, 2020.

doi: 10.21037/apm-19-409

View this article at: http://dx.doi.org/10.21037/apm-19-409

\section{Introduction}

Ankylosing spondylitis (AS) is a common chronic inflammatory rheumatic disease, mainly involved with the axial skeleton and adjacent soft tissues. It can cause characteristic inflammatory back pain, peripheral arthritis, enthesis, etc., and lead to structural and functional impairments and a decrease in quality of life. New imaging techniques and therapies have substantially changed the management of this disease in the past decade (1).

For most traditional treatment is ineffective AS patients, tumor necrosis factor $\alpha(\mathrm{TNF}-\alpha)$ inhibitors can quickly take 
control of synovitis, reduce pain and stiffness, even delay the destruction of cartilage and bone, improve patients' quality of life and reduce disability rate (2). It is difficult for most AS patients to afford long-term treatment costs. China has a high incidence of tuberculosis and hepatitis B, TNF- $\alpha$ inhibitors, long-term application, tuberculosis, and hepatitis $\mathrm{B}$ incidence are likely to rise (3-5). Therefore, it is necessary to search for drugs to effectively improve AS patient's condition and suitable for china's basic national conditions.

Moreover, since AS is often delayed healing or recurrent, patients often accompanied by anxiety, depression and sleep disorders, making AS more complicated and difficult to treat (6-8). Anxiety, depression and sleep disorders not only reduce the pain threshold, but they can also increase the severity of pain, enlarge body perceived function (including pain), impair patients' adaptation to pain for the tolerance (9-11). The reduction to cope with somatic disease capacity also has a negative impact on the treatment and rehabilitation programs of patient's desirability (12). Therefore, AS should take rational and effective integrated interventions to get the best efficacy.

Thalidomide is a relatively broad spectrum of immunosuppressants that can inhibit the inflammatory processes the interleukin (IL)-1, IL-6 and TNF- $\alpha$ produced $(13,14)$. Our previous studies have reported that thalidomide is safe and effective for refractory AS. Besides, there is no evidence to suggest that thalidomide will increase the chance of developing tuberculosis or hepatitis B at present $(15,16)$. People with anxiety, depression and sleep disturbances are associated with serum in the elevated of IL-1, IL-6 and the TNF- $\alpha$ (17-19). After injection with IL- 1 or TNF- $\alpha$, it can induce sleep deprivation or depression-like symptoms (20). Thalidomide may be treated AS the same time, but also have a positive effect on psychological symptoms and sleep disturbances. The study enrolled a larger sample size of refractory AS patients. Thalidomide was treated somatic symptoms of AS patient's efficacy and safety to determine whether it had a positive impact on refractory AS patients with psychological symptoms and sleep disorders.

We present the following article in accordance with the TREND reporting checklist (available at http://dx.doi. org/10.21037/apm-19-409).

\section{Methods}

\section{Subjects}

Long-term follow-up of AS patients was recruited from two rheumatology clinics and departments in Fujian Provincial Hospital. Inclusion criteria: (I) comply with the 1984 revision of New York AS classification criteria; (II) comply with disease activity standard: the scores of BASDAI $\geq 4$; (III) refractory AS standards: traditional therapies are not valid (including non-steroidal anti-inflammatory drugs, sulfasalazine, methotrexate, and corticosteroids, etc.), or adverse reactions could not be tolerated; (IV) the scores of nocturnal pain and total back pain $\geq 4$; (V) married with children or almost 2 years with no fertility requirements; (VI) normal liver and kidney function; (VII) ability to read and understand the contents of the questionnaires. Exclusion criteria: (I) combined with malignant tumors, Fibromyalgia syndrome, and other chronic somatic diseases; (II) associated with other mental illnesses. Before starting the medication, patients were informed that they must take effective contraceptive measures during the use of thalidomide. The study was conducted safety and security in accordance with the United States Celgene Corporation formulated of thalidomide education and Prescription safety system (STEPS) standard. This study was approved by the ethics committee of Fujian Provincial Hospital (approval ID: K-2018-10-014) and conducted in accordance with the Declaration of Helsinki (as revised in 2013). All the subjects included in this study have been informed in detail and signed the informed consent.

\section{Clinical evaluations}

All enrolled patient's age, gender, duration, and other information, and physical status, psychological and sleep were recorded and assessed at baseline, 3 months and 6 months. Blood samples were taken to measure ESR, CRP level. The pain included nocturnal pain; last week/spine/at night due to AS, total back pain; last week/spine/due to AS). The pain score was determined from a visual analog scale (VAS), recording from $0 \mathrm{~cm}$ (none) to $10 \mathrm{~cm}$ (very severe). The revised SAS was used to evaluate the level of anxiety-related symptoms during the last week before the survey. This selfadministered test has 20 questions, with 15 items worded toward increasing anxiety levels and five questions worded toward decreasing anxiety levels. Each question was scored on a scale of 1-4 (rarely, sometimes, frequently, and always).

The scores ranged between 20 and 80 . A score of 50-69 shows the existence of anxiety, and a score of 70 or above means extreme anxiety was used to assess anxiety Symptoms, SAS standard score $>50$ who had symptoms of anxiety (21); The depression levels of the patients were evaluated using 
SDS. This scale consists of 20 questions that examine the somatic, affective, and psychological symptoms associated with depression. Each question is scored between 1 and 4 (rarely, sometimes, frequently, and always). The total score varies between 20 and 80 . Higher scores reflected more severe depression. A score of 50-69 shows the existence of depression, and a score of 70 or above means extreme depression (22).

Sleep during the month preceding the evaluation was examined using the Pittsburgh Sleep Quality Index (PSQI), which includes 19 questions completed by the subject. These 19 items were broken down into the following seven components: subjective sleep quality, sleep latency, sleep duration, habitual sleep efficiency, sleep disorders, use of hypnotics, and daytime dysfunction. Sleep latency is assessed by two questions rated according to time to fall asleep. Sleep duration by one question rated by a four Likert scale from $>7$ to $<5 \mathrm{~h}$, and sleep efficiency by hours asleep divided by a total of hours in bed. Use of hypnotics and poor daytime functioning are rated by a four Likert scale (not during the past month, less than once a week, once or twice a week, three or more times a week). Sleep disorders are assessed by 9 questions focused on: waking up in the middle of the night or early in the morning, getting up to go to the toilet, difficulty breathing properly, coughing or snoring loudly, being too cold, being too hot, having nightmares, experiencing pain, other reason disturbing sleep. Each question is rated by a four Likert scale (not during the past month, less than once a week, once or twice a week, three or more times a week). Subjective sleep is evaluated by one question rated by a four Likert scale from very good to very bad. The seven components were each scored from 0 (no difficulty) to 3 (severe difficulty), and summed, to give an overall score ranging from 0 to 21 . PSQI score $>7$ who had sleep disorder (23).

\section{Drug intervention}

Thalidomide (Changzhou pharmaceutical factory, $50 \mathrm{mg} /$ tablet) was used $50 \mathrm{mg} / \mathrm{d}$ as an initial dose before sleep. Every $7 \mathrm{~d}$ increased by $50 \mathrm{mg} / \mathrm{d}$ until it reached $150 \mathrm{mg} / \mathrm{d}$. Before starting treatment with thalidomide, patients were taking all Disease-Modifying Antirheumatic Drugs (DMARDs) should be discontinued. Non-steroidal anti-inflammatory drugs could be maintained, but dose could not be increased. Symptoms Controlled can be discretionary reductions, with a minimum effective dose to maintain. If the patient appeared suspicious neuritis symptoms such as numbness, tingling, and others, thalidomide would be stopped treatment.

\section{Statistical analysis}

The data were analyzed using the Statistical Package for the Social Sciences (SPSS) version 17.0, disease-related parameters using descriptive statistics. The data of baseline, 3 months and 6 months were used with analysis of variance, rate of comparison was tested with chi-square test, the statistical significance level was considered at $\mathrm{P}<0.05$.

\section{Results}

\section{Patient characteristics}

Forty-one patients were recruited in the study, 35 patients (31 men, 4 women) with AS completed the clinical trials, their age was $21-46$ years (mean age was $32.23 \pm 5.74$ years), and their disease duration was 1-19 years (mean disease duration was $7.00 \pm 4.26$ years).

\section{Effectiveness and adverse reactions of thalidomide}

Thirty-five consecutive patients with AS completed the study, there were 10 patients in which had no adverse reactions. There may be relevant with adverse reactions of thalidomide during follow-up (arranged by frequency of occurrence from most to least), including: drowsiness (10/35), dry mouth (8/35), constipation (8/35), dandruff (7/35), dizziness (4/35), skin rash (4/35), abdominal pain $(3 / 35)$. The remaining rare side effects: decreased libido $(1 / 35)$, hand tremors $(1 / 35)$, memory decline $(1 / 35)$, blurred vision (1/35), unresponsive (1/35), nausea and bloating $(1 / 35)$. Six patients withdrew from the study because of adverse events, there were the main adverse reactions (arranged by frequency of occurrence from most to least), including: numbness (3/6), numbness around the lips (2/6), skin rash (2/6), drowsiness (2/6), dizziness (1/6), tingling fingertips (1/6).

Thalidomide was used to treat at baselines, the end of $3^{\text {rd }}$ month and the end of the $6^{\text {th }}$ month within each detection index comparisons between groups Variance analysis showed. The levels of ESR, CRP, nocturnal pain, total body pain, BASDAI, BASFI, BASMI, fingertip-to-floor distance, SAS, SDS, PSQI in AS patients were statistical significance among comparisons between groups (Table 1). Each detection index of AS patients was a pairwise comparison at baselines, the end of $3^{\text {rd }}$ month and the end of $6^{\text {th }}$ month. 
Table 1 AS patients at baselines, the end of $3^{\text {rd }}$ month and the end of $6^{\text {th }}$ month within each detection index comparisons between groups

\begin{tabular}{|c|c|c|c|c|c|c|c|c|c|c|c|}
\hline Variables & $\mathrm{ESR}^{\star}$ & $\mathrm{CRP}^{\star}$ & $\begin{array}{l}\text { Nocturnal } \\
\text { pain* }^{*}\end{array}$ & $\begin{array}{c}\text { Total body } \\
\text { pain* }^{*}\end{array}$ & BASDAl $^{*}$ & BASFI & BASMI* $^{*}$ & $\begin{array}{l}\text { Fingertip-to- } \\
\text { floor distance }\end{array}$ & SAS & SDS & PSQI $^{*}$ \\
\hline Baselines & $23.4 \pm 24.7$ & $2.7 \pm 2.2$ & $7.7 \pm 1.7$ & $6.6 \pm 2.1$ & $5.6 \pm 1.3$ & $4.0 \pm 2.6$ & $2.1 \pm 2.0$ & $19.5 \pm 9.5$ & $51.7 \pm 9.3$ & $55.1 \pm 9.5$ & $7.2 \pm 3.6$ \\
\hline End of $6^{\text {th }}$ month & $7.1 \pm 4.8$ & $0.8 \pm 0.8$ & $3.0 \pm 1.6$ & $2.8 \pm 1.0$ & $2.9 \pm 1.1$ & $1.8 \pm 1.8$ & $0.9 \pm 1.4$ & $5.9 \pm 7.2$ & $43.3 \pm 7.9$ & $43.0 \pm 6.5$ & $4.5 \pm 1.9$ \\
\hline
\end{tabular}

Values are shown as mean \pm standard deviation. * , heterogeneity of variance. ESR, erythrocyte sedimentation rate; CRP, C-reactive protein; BASDAI, Bath Ankylosing Spondylitis Disease Activity Index; BASFI, Bath Ankylosing Spondylitis Functional Index; BASMI, Bath Ankylosing Spondylitis Metrology Index; SAS, Self-rating Anxiety Scale; SDS, Self-rating Depression Scale; PSQI, Pittsburgh Sleep Quality Index.

\section{The end of $3^{\text {rd }}$ month compared with baseline values}

Thalidomide was used to treat AS patients. All clinical parameters, including ESR, CRP, nocturnal pain, total body pain, BASDAI, BASFI, fingertip-to-floor distance, SDS, SAS and PSQI, had significantly lower levels at month 3 when compared to initial levels. The difference was statistically significant $(\mathrm{P}<0.05)$. But there was no statistical difference in BASMI consistently $(\mathrm{P}>0.05)$.

\section{The end of $6^{\text {th }}$ month compared with baseline values}

Thalidomide was used to treat AS patients, all of the Clinical parameters, included ESR, CRP, nocturnal pain, total body pain, BASDAI, BASFI, BASMI, fingertip-tofloor distance, SAS, SDS and PSQI, significantly lower levels of month 6 were found when compared to initial levels, the difference was statistically significant $(\mathrm{P}<0.05)$.

\section{The end of $6^{\text {th }}$ month compared with the end of $3^{\text {rd }}$ month}

The levels of ESR, CRP, BASMI, BASFI, SAS and PSQI were no significant change at the end of $6^{\text {th }}$ month $(\mathrm{P}>0.05)$. But the levels of nocturnal pain, total body pain, BASDAI, fingertip-to-floor distance, and SDS, at $3^{\text {rd }}$ month, decreased significantly when compared with those of the 6th month $(\mathrm{P}<0.05)($ Table 2).

\section{The numbers of AS patients accompanied by depression, anxiety, and sleep disorders were paired wise comparison at baselines, the end of $3^{\text {rd }}$ month and the end of $6^{\text {th }}$ month}

There were 18 patients (51\%) suffering from anxiety symptoms, 23 patients $(66 \%)$ suffering from depressive symptoms, and 15 patients (43\%) suffering from sleep disorders, at baselines. At the end of $3{ }^{\text {rd }}$ month, there were 12 patients (35\%) suffering from anxiety symptoms, fourteen patients (40\%) suffering from depressive symptoms, and 2 patients $(6 \%)$ suffering from sleep disorders. At the end of $6^{\text {th }}$ month, there were 6 patients $(17 \%)$ suffering from anxiety symptoms, 5 patients (14\%) suffering from depressive symptoms, and 4 patients (11\%) suffering from sleep disorders. The number of AS patients accompanied by anxiety, depression, and sleep disorders, at $3^{\text {rd }}$ month reduced significantly when compared with those of baselines $(\mathrm{P}<0.05)$. The number of AS patients accompanied by anxiety, depression and sleep disorders, at $6^{\text {th }}$ month reduced significantly when compared with those of baselines $(\mathrm{P}<0.05)$. Patients with depression, at $3^{\text {rd }}$ month improved further when compared with this of the $6^{\text {th }}$ month $(\mathrm{P}<0.05)$, But not anxiety and sleep disorders $(\mathrm{P}>0.05)$ (Table 3$)$.

\section{Discussion}

There are few research reports on thalidomide for treating AS. This study is had further observation on efficacy and safety of thalidomide in patients with refractory AS physical, psychological symptoms and sleep disturbances (15). Studies have shown that thalidomide in the body by inhibiting the expression of TNF-mediated NF- $\mathrm{KB}$ and the expression of other genes regulated by NF- $\mathrm{BB}$ reduce the production of TNF- $\alpha$, and TNF- $\alpha$ is an important cytokine involved in the inflammatory activity of AS (24). Small-scale clinical studies have shown that thalidomide is effective for a variety of rheumatic diseases, such as Systemic Juvenile Idiopathic Arthritis, skin manifestations of Systemic Lupus Erythematosus, Behcet's Disease, Crohn's disease, etc. Efficacy of thalidomide is poor in the treatment of 
Table 2 Each detection index of AS patients was a pairwise comparison at baselines, the end of $3^{\text {rd }}$ month and the end of $6^{\text {th }}$ month

\begin{tabular}{lccc}
\hline Variables & $\begin{array}{c}\text { Baselines vs. end of } \\
3^{\text {rd }} \text { month }(\mathrm{P})\end{array}$ & $\begin{array}{c}\text { Baselines vs. end of } \\
6^{\text {th }} \text { month }(\mathrm{P})\end{array}$ & $\begin{array}{c}\text { End of } 3^{\text {rd }} \text { month vs. end of } \\
6^{\text {th }} \text { month }(\mathrm{P})\end{array}$ \\
\hline ESR $^{*}$ & 0.01 & 0.001 & 0.475 \\
CRP $^{*}$ & 0.071 & 0.002 & 0.272 \\
Nocturnal pain* & $<0.001$ & $<0.001$ & 0.029 \\
Total body pain* & 0.003 & $<0.001$ & 0.001 \\
BASDAl* $^{*}$ & 0.002 & $<0.001$ & 0.015 \\
BASFI $^{*}$ & 0.001 & $<0.001$ & 0.539 \\
BASMI* & 0.475 & 0.014 & 0.253 \\
Fingertip-to-floor distance & $<0.001$ & $<0.001$ & 0.003 \\
SDS & 0.001 & $<0.001$ & 0.013 \\
SAS & 0.005 & $<0.001$ & 0.238 \\
PSQl & $<0.001$ & 0.001 & 0.985 \\
\hline
\end{tabular}

*, using Dunnett T3 test. ESR, erythrocyte sedimentation rate; CRP, C-reactive protein; BASDAI, Bath Ankylosing Spondylitis Disease Activity Index; BASFI, Bath Ankylosing Spondylitis Functional Index; BASMI, Bath Ankylosing Spondylitis Metrology Index; SAS, Selfrating Anxiety Scale; SDS, Self-rating Depression Scale; PSQI, Pittsburgh Sleep Quality Index.

Table 3 The number of AS patients accompanied by depression, anxiety, and sleep disorders were paired wise comparison at baselines, the end of $3^{\text {rd }}$ month and the end of $6^{\text {th }}$ month

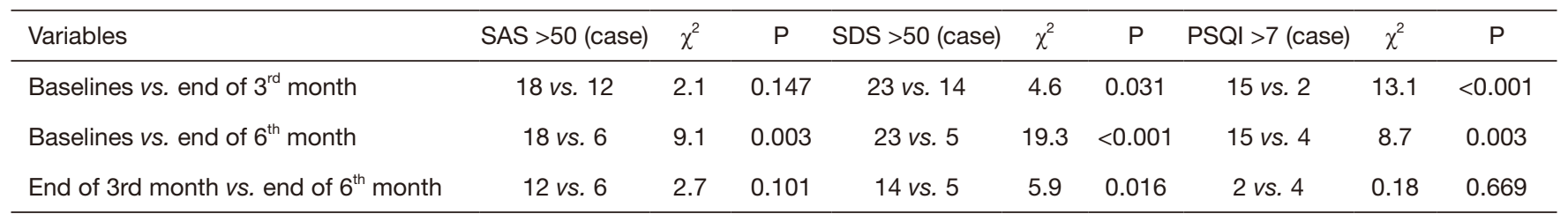

SAS, Self-rating Anxiety Scale; SDS, Self-rating Depression Scale; PSQI, Pittsburgh Sleep Quality Index.

rheumatoid arthritis (25-27).

The study has shown that patients with laboratory parameters ESR, CRP. somatic symptoms such as nocturnal pain, total back pain. BASDI, BASFI, BASMI, fingertip-tofloor distance were significantly improved compared with baseline. This is similar to our previous research results (15).

Thalidomide is originally used as one of non-barbiturate hypnotics and has a good improvement nighttime sleep function, to improve the role of anxiety and depression is partly attributed to the improvement of sleep disorders. Sleep problems are usually depression and anxiety of the main complaint. Early awakening is the core symptom of depression, and difficulty falling asleep is the main symptom of anxiety disorders (28-30).

Our previous studies found that AS patients with sleep disorders than those without sleep disorders had significantly higher anxiety and depression scores (7).
Sleep disorders, anxiety, and depression symptoms are significantly improved to a great extent also benefit from therapeutic role of thalidomide on AS. Thalidomide has significant improvement effect on active refractory AS pain, physical function, disease activity index and inflammatory markers, therefore, it is not difficult to understand that thalidomide can improve on AS accompanied with sleep disorders, anxiety, and depression. Anxiety, depression and sleep disorders of pathophysiologic mechanisms with some of the elevated proinflammatory cytokines are inseparable.

Abedelmalek et al. (31) reported that their plasma of proinflammatory cytokines TNF- $\alpha$ and IL- 1 would increase secretion after 30 healthy football players were partial sleep deprivation. On the contrary, by injecting exogenous TNF- $\alpha$, IL-1, and IL- 6 , the subject appeared insomnia, drowsiness, fatigue, cognitive decline and other symptoms $(20,32)$. In clinical practice, etanercept, infliximab, 
and adalimumab are used to treat patients with active inflammation and can improve resistance activity AS patients with anxiety, depression and sleep disorders (33-35). Kaster et al. (36) reported that TNF- $\alpha$ in mice induced depressionlike symptoms, which could be completely blocked by thalidomide. In addition to TNF- $\alpha$, IL- 1 and IL- 6 are also involved in the occurrence of sleep disorders, anxiety and depression (37), and thalidomide also can inhibit these pro-inflammatory cytokines (38). May be due to the above mechanism, after the application of thalidomide, active refractory AS accompanied by anxiety, depression and sleep disorders have been significantly improved. About security aspects of thalidomide, six patients withdrew from the study because of adverse events, the three patients had neuritis performance, such as extremity, lips numb or tingling fingertips and so on, and the remaining three cases appeared to be difficult to tolerating skin rash, drowsiness or dizziness.

Thirty-five consecutive patients with AS completed the study, 10 patients had no adverse reactions. In the study, we observed that the most tolerable common adverse reactions were drowsiness (10/35), dry mouth (8/35), constipation (8/35), dandruff (7/35), dizziness (4/35), skin rash (4/35), abdominal pain (3/35), decreased libido (1/35), hand tremors $(1 / 35)$, memory decline $(1 / 35)$, blurred vision (1/35), unresponsive (1/35), nausea and bloating (1/35) For solving the problem of drowsiness, we inform patients early to bed and early to rise, to drink a cup of coffee or tea after shower in order to improve daytime drowsiness. For solving the problem of constipation, in addition to told to eat food containing dietary fiber, to treat AS at the same time can be combined with total glucosides of Paeony which diarrhea is a common adverse reaction to improve constipation (39). One case of hand tremor in patients because of mild symptoms, the patient continued to use the Medication and hand tremor disappeared after a month.

\section{Conclusions}

In summary, refractory AS patients not only have somatic symptoms but are also accompanied by anxiety, depression, and sleep disorders. Thalidomide can improve effectiveness and safety in the treatment of physical, psychological symptoms and sleep disturbances accompanying refractory AS.

\section{Acknowledgments}

Funding: This project was supported by the Natural Science
Foundation of Fujian Province, China (No. 2020J011077).

\section{Footnote}

Reporting Checklist: The authors have completed the TREND Reporting Checklist. Available at http://dx.doi. org/10.21037/apm-19-409

Data Sharing Statement: Available at http://dx.doi. org/10.21037/apm-19-409

Conflicts of Interest: All authors have completed the ICMJE uniform disclosure form (available at http://dx.doi. org/10.21037/apm-19-409). The authors have no conflicts of interest to declare.

Ethical Statement: The authors are accountable for all aspects of the work in ensuring that questions related to the accuracy or integrity of any part of the work are appropriately investigated and resolved. The study was conducted safety and security in accordance with the United States Celgene Corporation formulated of thalidomide education and Prescription safety system (STEPS) standard. This study was approved by the ethics committee of Fujian Provincial Hospital (Approval ID: K-2018-10-014) and conducted in accordance with the Declaration of Helsinki (as revised in 2013). All the subjects included in this study have been informed in detail and signed the informed consent.

Open Access Statement: This is an Open Access article distributed in accordance with the Creative Commons Attribution-NonCommercial-NoDerivs 4.0 International License (CC BY-NC-ND 4.0), which permits the noncommercial replication and distribution of the article with the strict proviso that no changes or edits are made and the original work is properly cited (including links to both the formal publication through the relevant DOI and the license). See: https://creativecommons.org/licenses/by-nc-nd/4.0/.

\section{References}

1. Zhang S, Li Y, Deng X, et al. Similarities and differences between spondyloarthritis in Asia and other parts of the world. Curr Opin Rheumatol 2011;23:334-8.

2. Huang F, Gu J, Zhu P, et al. Efficacy and safety of adalimumab in Chinese adults with active ankylosing spondylitis: results of a randomised, controlled trial. Ann Rheum Dis 2014;73:587-94. 
3. Isaacs D. Infectious risks associated with biologics. Adv Exp Med Biol 2013;764:151-8.

4. Cheng JQ, Ma HW, Xie X, et al. Sero-epidemiological investigation on hepatitis $\mathrm{B}$ among permanent residents in Shenzhen area. Zhonghua Liu Xing Bing Xue Za Zhi 2013;34:1179-82.

5. Wang L, Zhang H, Ruan Y, et al. Tuberculosis prevalence in China, 1990-2010; a longitudinal analysis of national survey data. Lancet 2014;383:2057-64.

6. Zhang SL, Li Y, Zhu J, et al. Relationship between sleep quality and nocturnal pain in ankylosing spondylitis. Zhonghua Yi Xue Za Zhi 2013;93:970-2.

7. Li Y, Zhang S, Zhu J, et al. Sleep disturbances are associated with increased pain, disease activity, depression, and anxiety in ankylosing spondylitis: a case-control study. Arthritis Res Ther 2012;14:R215.

8. Li Y, Zhang SL, Zhu J, et al. Impact of duloxetine on depression and anxiety in patients with ankylosing spondylitis: a case-control study. Zhonghua Yi Xue Za Zhi 2013;93:966-9.

9. Annagür BB, Uguz F, Apiliogullari S, et al. Psychiatric disorders and association with quality of sleep and quality of life in patients with chronic pain: a SCID-based study. Pain Med 2014;15:772-81.

10. Salazar A, Dueñas M, Ojeda B, et al. Association of painful musculoskeletal conditions and migraine headache with mental and sleep disorders among adults with disabilities. Prev Chronic Dis 2014;11: E30.

11. Batmaz I, Sarıyıldız MA, Dilek B, et al. Sleep quality and associated factors in ankylosing spondylitis: relationship with disease parameters, psychological status and quality of life. Rheumatol Int 2013;33:1039-45.

12. Rodríguez-Lozano C, Gantes MÁ, González B et al. Patient-acceptable symptom state as an outcome measure in the daily care of patients with ankylosing spondylitis. J Rheumatol 2012;39:1424-32.

13. De Sanctis JB, Mijares M, Suárez A, et al. Pharmacological properties of thalidomide and its analogues. Recent Pat Inflamm Allergy Drug Discov 2010;4:144-8.

14. Kawai T, Watanabe N, Yokoyama M, et al. Thalidomide attenuates excessive inflammation without interrupting lipopolysaccharide-driven inflammatory cytokine production in chronic granulomatous disease. Clin Immunol 2013;147:122-8.

15. Huang F, Gu J, Zhao W, et al. One-year open-label trial of thalidomide in ankylosing spondylitis. Arthritis Rheum 2002;47:249-54.

16. Choudhury MR, Hassan MM, Kabir ME, et al. An open label clinical trial of thalidomide in NSAIDs refractory ankylosing spondylitis. Mod Rheumatol 2018;28:730-2 .

17. Leonard B, Maes M. Mechanistic explanations how cellmediated immune activation, inflammation and oxidative and nitrosative stress pathways and their sequels and concomitants play a role in the pathophysiology of unipolar depression. Neurosci Biobehav Rev 2012;36:764-85.

18. Hashmi AM, Butt Z, Umair M. Is depression an inflammatory condition? A review of available evidence. J Pak Med Assoc 2013;63:899-906.

19. Lemos VA, dos Santos RV, Lira FS, et al. Can high altitude influence cytokines and sleep? Mediators Inflamm 2013;2013:279365.

20. Krueger JM. The role of cytokines in sleep regulation. Curr Pharm Des 2008;14:3408-16.

21. Zung WWK. A rating instrument for anxiety disorders. Psychosomatics 1971;12:371-9.

22. Zung WWK. A self-rating depression scale. Arch Gen Psychiatry 1965;12:63-70.

23. Buysse DJ, Reynolds CF, Monk TH, et al. The pittsburgh sleep quality index: a new instrument for psychiatric practice and research. Psychiatry Res 1989;28:193-213.

24. Majumder S, Sreedhara SR, Banerjee S, et al. TNF $\alpha$ signaling beholds thalidomide saga: a review of mechanistic role of TNF- $\alpha$ signaling under thalidomide. Curr Top Med Chem 2012;12:1456-67.

25. Ossandon A, Cassarà EA, Priori R, et al. Thalidomide: focus on its employment in rheumatologic diseases.Clin Exp Rheumatol 2002;20:709-18.

26. Sathe K, Khubchandani RP. Thalidomide for systemic onset juvenile idiopathic arthritis. Indian Pediatr 2013;50:237-9.

27. Lehman TJ. Thalidomide for rheumatic disease: the best of both worlds? Nat Clin Pract Rheumatol 2007;3:308-9.

28. Lovell GP, Nash K, Sharman R, et al. A cross-sectional investigation of depressive, anxiety, and stress symptoms and health-behavior participation in Australian university students. Nurs Health Sci 2015;17:134-42.

29. Kushnir J, Marom S, Mazar M, et al. The link between social anxiety disorder, treatment outcome, and sleep difficulties among patients receiving cognitive behavioral group therapy. Sleep Med 2014;15:515-21.

30. Tkachenko O, Olson EA, Weber M, et al. Sleep difficulties are associated with increased symptoms of psychopathology. Exp Brain Res 2014;232:1567-74.

31. Abedelmalek S, Souissi N, Chtourou H, et al. Effects of partial sleep deprivation on proinflammatory cytokines, 
growth hormone, and steroid hormone concentrations during repeated brief sprint interval exercise. Chronobiol Int 2013;30:502-9.

32. Späth-Schwalbe E, Hansen K, Schmidt F, et al. Acute effects of recombinant human interleukin-6 on endocrine and central nervous sleep functions in healthy men. J Clin Endocrinol Metab 1998;83:1573-9.

33. Thaçi D, Galimberti R, Amaya-Guerra M, et al. Improvement in aspects of sleep with etanercept and optional adjunctive topical therapy in patients with moderate-to-severe psoriasis: results from the PRISTINE trial. J Eur Acad Dermatol Venereol 2014;28:900-6.

34. Zamarrón C, Maceiras F, Mera A, et al. Effect of the first infliximab infusion on sleep and alertness in patients with active rheumatoid arthritis. Ann Rheum Dis 2004;63:88-90.

35. Strober BE, Sobell JM, Duffin KC, et al. Sleep quality

Cite this article as: Zhang S, Chen Z, Wu Y, Lin D, He J, Liu J, Gao F, Lin H. Efficacy and safety of thalidomide on psychological symptoms and sleep disturbances in the patient with refractory ankylosing spondylitis. Ann Palliat Med 2021;10(3):2512-2519. doi: 10.21037/apm-19-409 and other patient-reported outcomes improve after patients with psoriasis with suboptimal response to other systemic therapies are switched to adalimumab: results from PROGRESS, an open-label Phase IIIB trial. Br J Dermatol 2012;167:1374-81.

36. Kaster MP, Gadotti VM, Calixto JB, et al. Depressivelike behavior induced by tumor necrosis factor- $\alpha$ in mice. Neuropharmacology 2012;62:419-26.

37. Bilbo SD, Schwarz JM. Early-life programming of laterlife brain and behavior: a critical role for the immune system. Front Behav Neurosci 2009;3:14.

38. Davis JC Jr, Huang F. New therapies for ankylosing spondylitis: etanercept, thalidomide, and pamidronate. Rheum Dis Clin North Am 2003;29:481-94.

39. Li CL, He J, Li ZG, et al. Effects of total glucosides of paeony for delaying onset of Sjogren's syndrome: an animal study. J Craniomaxillofac Surg 2013;41:610-5. 